\title{
Excess body fat increases the accumulation of advanced glycation end products in the skin of patients with type 1 diabetes
}

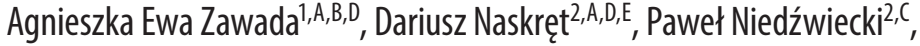 \\ Marian Grzymisławski ${ }^{1, E, F}$, Dorota Anna Zozulińska-Ziółkiewicz ${ }^{2, E, F}$, Agnieszka Dobrowolska ${ }^{1, E, F}$ \\ ${ }^{1}$ Department of Gastroenterology, Dietetics and Internal Medicine, Poznan University of Medical Sciences, Poland \\ ${ }^{2}$ Department of Internal Medicine and Diabetology, Poznan University of Medical Sciences, Poland \\ A - research concept and design; $\mathrm{B}$ - collection and/or assembly of data; $\mathrm{C}$ - data analysis and interpretation; \\ $D$ - writing the article; $E$ - critical revision of the article; $F$ - final approval of the article
}

Address for correspondence

Agnieszka Zawada

E-mail:a.zawada@ump.edu.pl

Funding sources

The project was supported by statutory funds (grant No. 502-01-023482-00-274) from

the Poznan University of Medical Sciences, Poland.

Conflict of interest

None declared

Received on December 6, 2019

Reviewed on July 4, 2020

Accepted on August 5, 2020

Published online on 0ctober 16, 2020

Cite as

Zawada AE, Naskręt D, Niedźwiecki P, Grzymisławski M, Zozulińska-Ziółkiewicz DA, Dobrowolska A. Excess body fat increases the accumulation of advanced glycation end products in the skin of patients with type 1 diabetes. Adv Clin Exp Med. 2020;29(10):1193-1199.

doi:10.17219/acem/126050

DOI

10.17219/acem/126050

Copyright

Copyright by Author(s)

This is an article distributed under the terms of the

Creative Commons Attribution 3.0 Unported (CC BY 3.0)

(https://creativecommons.org/licenses/by/3.0/)

\begin{abstract}
Background. The process of protein glycation described by Brownlee et al. is a crucial pathogenic mechanism in the development of chronic complications of diabetes.

Objectives. To assess advanced glycation end products (AGEs) in the skin of patients with type 1 diabetes (DM1) and excess body fat (EBF) accumulation.

Material and methods. The study group consisted of 227 DM1 patients (121 women and 106 men) whose mean age was $31 \pm 9.2$ years; the mean duration of diabetes was $12 \pm 7.7$ years; and the mean $\mathrm{HbAlc}$ was $8.9 \pm 1.8 \%$. The inclusion criteria were as follows: age 18-65 years, DM1, and lack of acute inflammations and uncontrolled chronic diseases. The exclusion criteria were: anemia (hemoglobin $(\mathrm{Hb})<11 \mathrm{~g} / \mathrm{dL}$ ), chronic kidney disease (CKD) (glomerular filtration rate (eGFR) $<30 \mathrm{~mL} / \mathrm{min} / 1.73 \mathrm{~m}^{2}$ ) and elevated aminotransferase levels (more than twice the upper normal limits). Total adipose tissue content was assessed using the electrical bioimpedance method, with the Tanita BC-418 MA analyzer (Tanita Corp., Tokyo, Japan). The Tanita ViScan AB 140 (Tanita Corp.) was used to evaluate visceral fat tissue (VTF). The content of glycation end products in the skin was assessed using a DiagnOptics AGE Reader device (type 214D00102; DiagnOptics, Groningen, the Netherlands).
\end{abstract}

Results. The group with normal body fat (NBF) consisted of 123 subjects, whereas 104 subjects had EBF. No significant statistical differences were found between the NBF and EBF groups with regard to age, duration of diabetes, current HbA1C value, and tobacco use. A significantly higher AGE score was observed in the EBF group.

Conclusions. Increased body fat affects the amount of AGE in the skin, which correlates with a higher risk of developing chronic diabetes complications.

Key words: advanced glycation end products, type 1 diabetes, excess body fat 


\section{Introduction}

The process of protein glycation, described by Brownlee et al. in the 1980s, is a crucial pathogenic mechanism in the development of chronic complications of diabetes. ${ }^{1}$ Permanent, irreversible advanced glycation end products (AGEs) characterized by a brownish coloration and specific spectrophotometric properties (specific wavelength fluorescence) are created as a result of a non-enzymatic Millard reaction. They show substantial immunogenicity, as well as the ability to bind with certain types of cells through membrane receptors. ${ }^{2}$ A correlation between protein glycation and micro- and macro-angiopathic diabetic complications has been observed. ${ }^{3,4}$ Furthermore, AGEs and increased expression of their receptors for advanced glycation end products (RAGEs) are directly correlated with loss of vessel wall elasticity, crystalline aggregations in the eye, disintegration of endothelial cells, and increased thickness of epicardial fat tissue. ${ }^{5,6}$

The number of AGEs in an organism can be evaluated directly by assessing their concentration in blood, and indirectly using their spectrophotometric properties skin autofluorescence (SAF) caused by the accumulation of protein glycation products. Evaluating the accumulation of AGEs in the skin based on SAF is a straightforward, non-invasive method that gives objective and reproducible results. ${ }^{7}$ Elevated AGEs in the skin in patients with diabetes are related to an increased risk of cardiovascular complications and are a better death predictability factor than glycated hemoglobin (HbA1c) or lipid parameters. ${ }^{8}$

The use of intensive functional insulin therapy (IFI) in the treatment of type 1 diabetes (DM1) decreases the risk of micro- and macroangiopathy. ${ }^{9}$ Sometimes the use of IFI is related to an increase in body mass and insulin resistance which, as a result, leads to the typical characteristics of metabolic syndrome. ${ }^{10}$ Eighteen years after the Pittsburgh Epidemiology of Diabetes Complications Study (EDC), an increased prevalence of overweight and obesity was observed. ${ }^{11}$ According to the World Health Organization (WHO) definition, metabolic syndrome was recognized by McGill et al. in 15\% of DM1 patients; according to the International Diabetes Federation (IDF) definition, Uruska et al. found it in $20 \%$ of patients with DM1. ${ }^{12,13}$ The highest frequency of metabolic syndrome (38\% of women and $40 \%$ of men with DM1) was noted according to the National Cholesterol Education Program (NECP) criteria. ${ }^{14}$ Observations have confirmed a relationship between metabolic syndrome and micro- and macroangiopathy in patients with DM1. ${ }^{14}$

The aim of the study was to assess AGEs in the skin of patients with DM1 and excess body fat (EBF) accumulation.

\section{Patients and methods}

The study group consisted of 227 DM1 patients (121 women and 106 men) treated in the Department of Internal Medicine and Diabetology at the Poznan
Table 1. Characteristics of the study group. The results are presented as numbers and percentages as well as medians and interquartile ranges (IQR)

\begin{tabular}{|l|c|}
\multicolumn{1}{|c|}{ Characteristics of the study group } & $n=227$ \\
\hline Gender, F/M & $121 / 106$ \\
\hline Age [years] & $29(23 ; 36)$ \\
\hline Duration of diabetes [years] & $10(6.0 ; 16)$ \\
\hline HbA1c $(\%)$ & $8.7(7.7-9.6)$ \\
\hline Creatinine $[\mu \mathrm{mol} / \mathrm{L}]$ & $74.3(65.4 ; 85.7)$ \\
\hline ALT $[\mathrm{U} / \mathrm{L}]$ & $17(12 ; 25)$ \\
\hline AST $[\mathrm{U} / \mathrm{L}]$ & $18(15 ; 23)$ \\
\hline TC $[\mathrm{mmol} / \mathrm{L}]$ & $5.1(4.4 ; 6.0)$ \\
\hline TG $[\mathrm{mmol} / \mathrm{L}]$ & $1.2(0.9 ; 1.5)$ \\
\hline HDL-C $[\mathrm{mmol} / \mathrm{L}]$ & $1.6(1.3 ; 1.9)$ \\
\hline LDL-C $[\mathrm{mmol} / \mathrm{L}]$ & $2.8(2.4 ; 3.5)$ \\
\hline Retinopathy, $\mathrm{n}(\%)$ & $74(32.5)$ \\
\hline Nephropathy, $\mathrm{n}(\%)$ & $24(10.6)$ \\
\hline Neuropathy, $\mathrm{n}(\%)$ & $39(17.1)$ \\
\hline
\end{tabular}

ALT - alanine aminotransferase; AST - aspartate aminotransferase; $\mathrm{HbA1c}$ - glycated hemoglobin A1c; HDL-C - high-density-lipoprotein cholesterol; LDL-C - low-density-lipoprotein cholesterol; TG - triglycerides; TC - total cholesterol.

University of Medical Sciences (Poland). Their mean age was $31 \pm 9.2$ years; the mean duration of diabetes was $12 \pm 7.7$ years. The study group presented poorly controlled diabetes; the mean HbA1c was $8.9 \pm 1.8 \%$. The detailed characteristics of the study group are presented in Table 1. All the patients gave written informed consent to participate in the study, which was approved by the Bioethics Committee of the Poznan University of Medical Sciences (approval No. 1040/10).

The inclusion criteria were as follows: age 18-65 years, DM1, and lack of acute inflammations and uncontrolled chronic diseases. The exclusion criteria were anemia (hemoglobin $(\mathrm{Hb})<11 \mathrm{~g} / \mathrm{dL})$, chronic kidney disease (CKD) (glomerular filtration rate $\left(\right.$ eGFR) $<30 \mathrm{~mL} / \mathrm{min} / 1.73 \mathrm{~m}^{2}$ ) and elevated aminotransferase levels (more than twice the upper normal limits).

Anthropometric parameters such as height [m] and body mass $[\mathrm{kg}]$ were evaluated in all the subjects of the study. The body mass index (BMI) $\left[\mathrm{kg} / \mathrm{m}^{2}\right]$, waist and hip circumference, and waist-to-hip ratio (WHR) were also determined. Systolic and diastolic blood pressure (SBP and DBP) were measured twice, sitting and after a five-minute rest. The measurement was performed with a sphygmometer using Korotkov's method [mm Hg]. The daily dosage of insulin was calculated the day before the study [number of units $/ \mathrm{kg} /$ day].

A venous blood sample was drawn in order to note the following parameters: fasting glucose in the venous blood serum and glucose in the venous blood serum $2 \mathrm{~h}$ after breakfast using the standard method; HbA1c using high performance liquid chromatography (HPLC); lipid parameters (total cholesterol (THc) level, levels of high-density 
lipoprotein (HDL) and low-density lipoprotein (LDL) fraction in the blood and triglyceride (TG) levels in the serum) using the enzymatic method; and aminotransferase activity (alanine aminotransferase - ALT, and aspartate aminotransferase - AST) in the serum using the standard method. The estimated glomerular filtration rate index (eGFR) was measured using the Modification of Diet in Renal Disease Study (MDRD) equation. All the laboratory tests were performed in the Raszeja Hospital Laboratory in Poznań.

The insulin resistance index - visceral adiposity index (VAI) and estimated glucose disposal rate (eGDR) - were calculated using the equations listed below:

- VAI in women: waist circumference/(36.58 + (1.89 $\times$ $\mathrm{BMI})) \times(\mathrm{TG} / 0.81) \times(1.52 / \mathrm{HDL})$;

- VAI in men: waist circumference/(39.68 + $(1.88 \times \mathrm{BMI}))$ $\times(\mathrm{TG} / 1.03) \times(1.31 / \mathrm{HDL})$;

- eGDR = 24.31-12.22 (WHR) - $3.29($ HA0/1) - 0.57 $[\mathrm{mg} / \mathrm{kg} / \mathrm{min}] .^{15}$

An eGDR value below $7.5 \mathrm{mg} / \mathrm{kg} / \mathrm{min}$ was considered an indicator of lowered tissue sensitivity to insulin action. ${ }^{16}$

Total adipose tissue content was assessed using the electrical bioimpedance method using a Tanita BC-418MA Body Composition Analyzer and a Tanita ViScan AB 140 (Tanita Corp., Tokyo, Japan). Total body fat (TBF) and visceral fat tissue (VFT) were assessed according to WHO age- and gender-adjusted criteria. ${ }^{17}$

The content of AGEs in the skin was evaluated using an AGE Reader Type 214D00102 (DiagnOptics, Groningen, the Netherlands). The device emits ultraviolet light at a wavelength of 300-420 nm, which illuminates $1 \mathrm{~cm}^{2}$ of skin on the inside of the forearm, about $10 \mathrm{~cm}$ from the elbow); a built-in spectrometer registers light in the 300-600 nm range. The autofluorescence (AF) score is calculated automatically.

\section{Statistical analysis}

The statistical analysis of the results was performed using STATISTICA PL v. 13.3 software (StatSoft Polska sp. z o.o., Kraków, Poland). The normality of the distribution of the results was tested using the Kolmogorov-Smirnov test with the Lilliefors correction. The parameters analyzed did not have normal distributions; therefore, nonparametric tests were used for further analysis. The results were presented as numbers and percentages as well as medians and interquartile ranges (IQR). In the case of numerical variables, differences between subgroups were analyzed using the Mann-Whitney test. Differences in qualitative data were assessed with the $X^{2}$ test. We used the multivariate regression method to analyze correlations between AGE level and selected parameters (such as sex, age, BMI, and the presence of chronic complications). In the correlation analysis, the Spearman correlation coefficients were used. A value of $\mathrm{p}<0.05$ was considered statistically significant.

\section{Results}

The normal body fat (NBF) group consisted of 123 subjects, whereas the EBF group included 104 subjects. Age and gender were taken into consideration in accordance with WHO norms. No significant statistical differences were found between the NBF and EBF groups with regard to age, duration of diabetes, current HbA1C value, daily dosage of insulin, and tobacco use.

The NBF and EBF groups were statistically different with regard to the following: anthropometric index (body mass, waist circumference, WHR), fasting blood glucose, blood glucose $2 \mathrm{~h}$ after eating, lipid parameters, and insulin resistance index (VAI, eGDR) (Table 2). A significantly higher AGE score was observed in the EBF group.

Statistically significant relationship was noted in the Spearmen correlation between lowered eGDR index (increased insulin resistance) and increased TBF, VBF and skin AGE (Table 3). The multifactor regression model showed the influence of VAI on the AGEs in the skin. It was gender-independent and disregarded chronic complications (Table 4).

\section{Discussion}

The Diabetes Control and Complications Trial (DCCT) published in 1993 revealed that intensive functional insulin therapy was the leading treatment to avoid microvascular complications (retinopathy and CKD) in patients with DM1. ${ }^{18}$ Improved metabolic control during the first 2 years of DM1 treated with intensive functional insulin therapy modified $\beta$ cell function and increased C-peptide, compared with conventional insulin treatment. ${ }^{19}$ However, these intensively treated subjects become more vulnerable to severe hypoglycemia and weight gain, accompanied by efforts to lower blood glucose with multiple insulin injections. The adverse consequences of undesirable weight gain accelerate the development of chronic complications, and increase blood pressure and the parameters of the lipid profile. The greatest metabolic damage is caused by the accumulation of VFT, which directly affects endothelial function in patients with either DM1 or DM2. This accelerates the development of atherogenic dyslipidemia. ${ }^{20,21}$ A study by den Engelsen et al. suggested that AGE accumulation in the skin can increase in populations with central obesity without diabetes. ${ }^{22}$ In this study, AGE skin levels were measured in 816 non-diabetic obese patients and in 431 patients without central obesity; the mean AGE index increased with age and smoking, and was significantly higher in patients with central obesity.

Earlier studies highlighted the increased accumulation of AGE in the skin in patients with DM2. Samborski et al. also demonstrated increased AGE content in the skin in patients with DM1 in comparison to patients not suffering from diabetes. ${ }^{23}$ However, a study by Dozio et al. 
Table 2. Comparison of the group with excess body fat (EBF) to the group with normal body fat (NBF). The results are presented as numbers and percentages as well as medians and interquartile ranges (IQR)

\begin{tabular}{|c|c|c|c|}
\hline Parameter & $\operatorname{NBF}(n=123)$ & $\operatorname{EBF}(n=104)$ & $p$-value \\
\hline Gender, F/M & $62 / 61$ & $59 / 45$ & 0.26 \\
\hline Age [years] & $30.5 \pm 9.2$ & $31.7 \pm 9.3$ & 0.28 \\
\hline Duration of diabetes [years] & $11.6 \pm 8.6$ & $12.4 \pm 6.3$ & 0.08 \\
\hline Retinopathy, n (\%) & $38(16.7)$ & $36(15.8)$ & 0.15 \\
\hline Nephropathy, n (\%) & $10(4.4)$ & $14(6.2)$ & 0.23 \\
\hline Neuropathy, n (\%) & $24(10.6)$ & $15(6.6)$ & 0.25 \\
\hline Smoking (\%) & 27.6 & 19.2 & 0.12 \\
\hline Daily insulin dosage [U/kg/day] & $0.5(0.4 ; 0.6)$ & $0.5 \pm 0.2$ & 0.71 \\
\hline $\mathrm{FPG}[\mathrm{mmol} / \mathrm{L}]$ & $8.2(5.4 ; 11.6)$ & $9.2(6.6 ; 12.1)$ & 0.04 \\
\hline PPG [mmol/L] & $9.5(6.4 ; 12.5)$ & $10.8(8.3 ; 13.6)$ & $<0.01$ \\
\hline $\mathrm{HbA1c}(\%)$ & $8.7(7.6 ; 9.8)$ & $8.6(7.7 ; 9.5)$ & 0.93 \\
\hline $\mathrm{HbA} 1 \mathrm{c}>7 \%, \mathrm{n}(\%)$ & $107(87)$ & $90(86)$ & 0.69 \\
\hline $\mathrm{HbA} 1 \mathrm{c} \leq 7 \%, \mathrm{n}(\%)$ & $16(13)$ & $14(14)$ & 0.69 \\
\hline Creatinine $[\mu \mathrm{mol} / \mathrm{L}]$ & $70.7(66.3 ; 85.7)$ & $75.1(65.4 ; 85.7)$ & 0.8 \\
\hline $\mathrm{eGFR}\left[\mathrm{mL} / \mathrm{min} / \mathrm{m}^{2}\right]$ & $99.5(88.4 ; 110.0)$ & $97.7(83.2 ; 105.6)$ & 0.24 \\
\hline $\mathrm{TCh}[\mathrm{mmol} / \mathrm{L}]$ & $5.2(4.5 ; 6.0)$ & $5.0(4.4 ; 5.9)$ & 0.6 \\
\hline $\mathrm{TG}[\mathrm{mmol} / \mathrm{L}]$ & $1.0(0.8 ; 1.4)$ & $1.3(1.0 ; 1.6)$ & $<0.01$ \\
\hline $\mathrm{HDL}-\mathrm{C}[\mathrm{mmol} / \mathrm{L}]$ & $1.7(1.4 ; 2.1)$ & $1.5(1.2 ; 1.7)$ & $<0.01$ \\
\hline LDL-C [mmol/L] & $2.8(2.2 ; 3.3)$ & $2.9(2.5 ; 3.6)$ & 0.03 \\
\hline BMI $\left[\mathrm{kg} / \mathrm{m}^{2}\right]$ & $23.0(21.2 ; 25.0)$ & $28.5(27.2 ; 31.3)$ & $<0.01$ \\
\hline WHR & $0.8(0.8 ; 0.9)$ & $0.9(0.9 ; 1.0)$ & $<0.01$ \\
\hline TBF $[k g]$ & $13.5(10.3 ; 16.8)$ & $27.5(22.3 ; 31.1)$ & $<0.01$ \\
\hline TBF (\%) & $19.6(15.1 ; 27.0)$ & $34.2(25.5 ; 38.1)$ & $<0.01$ \\
\hline $\operatorname{TRBF}[\mathrm{kg}]$ & $7.1(4.9 ; 9.0)$ & $14.6(12.6 ; 17.0)$ & $<0.01$ \\
\hline VBF, $n$ & $3.0(1.0 ; 4.0)$ & $7.0(5.0 ; 9.0)$ & $<0.01$ \\
\hline VAl, $n$ & $2.1(1.4 ; 3.0)$ & $3.6(2.3 ; 4.6)$ & $<0.01$ \\
\hline eGDR $[\mathrm{mg} / \mathrm{kg} / \mathrm{min}]$ & $7.8(6.0 ; 9.3)$ & $7.0(5.2 ; 8.3)$ & $<0.01$ \\
\hline AGEs, $n$ & $2.0(1.7 ; 2.3)$ & $2.1(1.9 ; 2.4)$ & 0.02 \\
\hline
\end{tabular}

FPG - fasting plasma glucose; PPG - postprandial plasma glucose; HbA1c - glycated hemoglobin; BMI - body mass index; eGDR - estimated glucose disposal rate; eGFR - estimated glomerular filtration rate; VAI - visceral adiposity index; AGEs - accumulation of advanced glycation end products; TRBF - trunk body fat; VBF - visceral body fat; TBF - total body fat; WHR - waist-to-hip ratio; HDL - high-density-lipoprotein cholesterol; LDL - low-densitylipoprotein cholesterol; TCh - total cholesterol.

Table 3. Correlations between selected parameters and the content of glycation end products in the skin

\begin{tabular}{|l|c|c|}
\multicolumn{1}{|c|}{ Parameter } & $\begin{array}{c}\text { Spearman's correlation } \\
\text { coefficient }\end{array}$ & p-value \\
\hline TBF (\%) & 0.19 & 0.004 \\
\hline VBF (\%) & 0.25 & 0.001 \\
\hline eGDR [mg/kg/min] & -0.16 & 0.016 \\
\hline
\end{tabular}

TBF - total body fat; VBF - visceral body fat; eGDR - estimated glucose disposal rate.

showed reduced content of soluble receptors for end products of protein glycation (sRAGEs) in obese women with waist circumferences $>80 \mathrm{~cm}$, higher fatty mass, epicardial adipose tissue, and VFT. ${ }^{24}$ In our study group of patients with DM1, Spearman's correlation demonstrated that increased TBF correlates with increased accumulation
Table 4. Analysis of the associations between selected parameters and AGEs content (univariate regression analysis)

\begin{tabular}{|l|c|c|}
\multicolumn{1}{|c|}{ Parameter } & $\beta$ coefficient & $p$-value \\
\hline Duration of diabetes [years] & 0.18 & 0.042 \\
\hline VBF $(\%)$ & 0.41 & 0.009 \\
\hline TBF $(\%)$ & 0.11 & 0.001 \\
\hline eGDR $[\mathrm{mg} / \mathrm{kg} / \mathrm{min}]$ & -0.16 & 0.01 \\
\hline
\end{tabular}

AGE - advanced glycation end-products; TBF - total body fat; VBF - visceral body fat; eGDR - estimated glucose disposal rate.

of AGEs in the skin. A similar relationship was also found for VAI. The occurrence of obesity and excess weight in patients with DM1 is inextricably linked to insulin resistance. Increased insulin dose adjustment and increased numbers of mealtime insulin injections contribute to the development of this condition in patients treated with IFI. In a study 
by Conway et al., the prevalence of obesity increased seven-fold with a nearly ten-fold increase in the frequency of intensive insulin therapy treatment. ${ }^{11}$ Insulin resistance is mostly connected with hypoglycemia, poorer metabolic control and increased risk of chronic complications such as CKD, retinopathy and cardiovascular disease (CVD). ${ }^{25}$ Our study also found a direct relationship between AGE content in the skin and the value of eGDR - the indirect insulin resistance index - in patients with DM1. Insulin, as a protein-structure hormone, is also subject to glycation processes. In a study by Jia et.al., it was shown that insulin glycation in the arginine position reduces the utilization of glucose by adipocytes and muscle cells. ${ }^{26}$

The AGEs of proteins are also produced in the bodies of healthy people. In patients with diabetes, they can be treated as a marker to assess the risk of complications. So far, the main marker used to assess metabolic control in diabetic patients is HbA1c. In a study by Monnier et al., it was shown that AGEs are more useful than HbA1c in the detection of late diabetic complications. ${ }^{27}$ These results are similar to those in our study, in which the EBF group presented a statistically comparable value of HbA1c to the group with NBF. However, both groups were characterized by poor diabetes control. Patients from both groups required intensification of treatment through the use of insulin analogs and re-education regarding IFI.

According to the latest guidelines of the Polish Diabetes Association, it is also possible to use sodium-glucose cotransporter-2 (SGLT2) inhibitors to treat patients with inadequately controlled DM1 and DM2 (DEPICT1 and DEPICT2). ${ }^{28}$ In clinical trials with SGLT2 inhibitors, statistically significant decreases in HbA1c, weight and total daily insulin dose were observed in both types of diabetes. ${ }^{29,30}$ The difference in AGE content between these 2 groups may also indicate the higher usefulness and accuracy of SAF compared to HbA1c as a prognostic marker in patients with diabetes, especially DM1. Araszkiewicz et al. showed a correlation between AGEs in the skin and the mean value of $\mathrm{HbA1c}$ in patients with DM1. ${ }^{4}$ As in our study, there was no correlation between one-time HbA1c and AGEs values. The relationship between earlier hyperglycemia and current skin AGE concentration may indicate the occurrence of metabolic memory in patients with DM1.

The AGEs are a stable parameter. A non-invasive assessment of AGEs in the skin may better reflect the toxic effects of hyperglycemia than the average glycemic values expressed as HbA1c. Proteins modified by AGEs may be more resistant to enzymatic degeneration, which promotes accumulation of AGEs in local tissue. ${ }^{31}$ Moreover, AGEs have been localized in retinal blood vessels in DM2 patients and found to correlate with the degree of retinopathy. ${ }^{32}$ Accumulation of these products in the body is also observed in patients with end-stage renal disease (ESRD). ${ }^{33}$ A correlation between AGE concentration in tissues and the severity of atherosclerotic lesions has been demonstrated: AGEs bind with apolipoprotein $\mathrm{B}$ and induces LDL retention in the aortic wall. ${ }^{34}$ A positive correlation has also been found between serum levels of AGEs and isovolumetric relaxation time measured during echocardiography in patients with DM1. ${ }^{35}$ The AGEs also correlate with intima-media thickness (IMT) in DM1 patients, and increase with CVD, other autoimmune diseases and inflammatory processes. ${ }^{36}$ Metabolic memory and overproduction of reactive oxygen species (ROS) play an important role AGE production, which may reflect metabolic control of diabetes over a longer period of time. ${ }^{37,38}$ In DM1, AGEs are a reliable marker of past glycemic control and their accumulation is connected with diabetic microangiopathy. ${ }^{39}$ In another study by Araszkiewicz et al., an association between SAF and long-term metabolic control and carotid IMT was revealed. ${ }^{36}$ Although many studies have shown an association between AGEs and late diabetic complications, in our study, the EBF and NBF groups did not differ in diabetic complications, and there were no correlations between AGEs and diabetic complications. ${ }^{7,40,41}$

A correlation between AGE concentration in tissue, severity of atherosclerotic lesion and increased retention of AGE-LDL in the aortic wall has also been demonstrated. ${ }^{42}$ The AGEs in DM2 are also inversely related to HDL anti-oxidative capacity. ${ }^{34,43}$ Our study revealed differences in lipid profiles in the EBF and NBF groups, but there was no statistical correlation between lipid profile and AGE accumulation.

It has been shown that ageing correlates with high rates of AGE formation and accumulation. ${ }^{44}$ Accumulation of AGEs is also a reliable biomarker of in vivo ageing. Accumulation of AGEs inside cells and tissues reflects a reaction between the intensity of inflammatory processes, modification of proteins like albumin or collagen, and modification of the proteasomal and lysosomal pathways.

In addition, high amounts of intracellular AGEs inhibit active immuno-proteasomes through the involvement of RAGEs and the Janus kinase 2/signal transducer and activator of transcription 1 (JAK2/STAT1) signaling pathway. ${ }^{45}$ It is worth noting that the concentration of immunoproteasome is higher in aged cells. ${ }^{46}$ In the aforementioned study by Araszkiewicz et al., a positive correlation was found between SAF and patient age. ${ }^{31}$ In our study, this correlation was not confirmed.

A study by Schram et al. among patients with DM1 found no correlation between AGEs and mean arterial pressure. ${ }^{47}$ Skin and blood AGEs were strongly and independently associated with pulse pressure. This is probably connected with arterial stiffness. In our study, we did not observe any differences in blood pressure in patients with or without EBF, nor between hypertension and AGEs.

\section{Conclusions}

Skin autofluorescence is simple to evaluate, and offers a valuable prognostic marker of the risk of developing chronic complications of diabetes. Increased body fat 
content affects the amount of AGEs in the skin, which is associated with a higher risk of developing chronic diabetes complications. In patients with DM1, it is important to maintain proper body weight in order to avoid increasing the risk of chronic complications.

The study has some limitations. Firstly, no prospective observation was performed. Secondly, the results obtained are limited by the lack of a control group. However, AGEs are always higher in populations with diabetes, which is why we did not recruit a control group without diabetes. Moreover, an indirect method was used to assess insulin resistance (eGDR, not the gold standard glucose clamp technique); however, the 2 methods are comparable.

An advantage of the study is that it involved a homogenous group of patients with autoimmune disease treated with intensive functional insulin pen therapy.

\section{ORCID iDs}

Agnieszka Ewa Zawada (1) https://orcid.org/0000-0001-6995-090X Dariusz Naskręt @ https://orcid.org/0000-0002-6927-7812 Paweł Niedźwiecki (1) https://orcid.org/0000-0002-4033-0085 Marian Grzymisławski (1) https://orcid.org/0000-0003-0868-354X Dorota Anna Zozulińska-Ziółkiewicz (1) https://orcid.org/0000-00032995-9971

Agnieszka Dobrowolska (10) https://orcid.org/0000-0002-3647-5070

\section{References}

1. Brownlee M, Cerami A, Vlassara H. Advanced glycosylation end products in tissue and the biochemical basis of diabetic complications. New Engl J Med. 1988;318(20):1315-1321.

2. Pietkiewicz J, Seweryn E, Bartyś A, Gamian A. Receptors for advanced glycation end products and their physiological and clinical significance. Postepy Hig Med Dosw. 2008;62:511-523.

3. Osawa S, Katakami N, Sato I, et al. Skin autofluorescence is associated with vascular complications in patients with type 2 diabetes. J Diabetes Complications. 2018;32(9):839-844.

4. AraszkiewiczA,NaskretD, NiedzwieckiP,SamborskiP,Wierusz-WysockaB, Zozulińska-Ziółkiewicz D. Increased accumulation of skin advanced glycation end products is associated with microvascular complications in type 1 diabetes. Diabetes Technol Ther. 2011;13(8):837-842.

5. Dozio $E$, Vianello E, Briganti S, et al. Expression of the receptor for advanced glycation end products in epicardial fat: Link with tissue thickness and local insulin resistance in coronary artery disease. J Diabetes Res. 2016;2016:2327341.

6. Nathan DM, Genuth S, Lachin J, et al. The Diabetes Control and Complications Trial Research Group. The effect of intensive treatment of diabetes on development and progression of long-term complications in insulin dependent diabetes mellitus. N Eng J Med. 1993;329:977-986.

7. Bos D, deRanitz-Greven W, deValk H. Advanced glycation end products, measured as skin autofluorescence and diabetes complications: A systematic review. Diabetes Technol Ther. 2011;13(7):773-779.

8. Lutgers HL, Gerrits EG, Graft R, et al. Skin autofluorescence provides additional information to the UK Prospective Diabetes Study (UKPDS) risk score for the estimation of cardiovascular prognosis in type 2 diabetes mellitus. Diabetologia. 2005;52(5):789-797.

9. Nathan DM, Genuth S, Lachin J, et al; Diabetes Control and Complications Trial Research Group. The effect of intensive treatment of diabetes on the development and progression of long-term complications in insulin-dependent diabetes mellitus. N Engl J Med. 1993;329(14): 977-986.

10. Purnell JQ, Zinman B, Brunzell JD; DCCT/EDIC Research Group. The effect of excess weight gain with intensive diabetes mellitus treatment on cardiovascular disease risk factors and atherosclerosis in type 1 diabetes mellitus: Results from the Diabetes Control and Complications Trial/Epidemiology of Diabetes Interventions and Complications Study (DCCT/EDIC) study. Circulation. 2013;127(2):180-187.
11. Conway B, Miller R, Costacou T, et al. Temporal patterns in overweight and obesity in type 1 diabetes. Diabet Med. 2010;27(4):398-404.

12. McGill M, Molyneaux L, Twigg SM, Yue DK. The metabolic syndrome in type 1 diabetes: Does it exist and does it matter? J Diabetes Complications. 2008;22(1):18-23.

13. Uruska A, Araszkiewicz A, Zozulinska-Ziolkiewicz D, Uruski P, WieruszWysocka B. Insulin resistance is associated with microangiopathy in type 1 diabetic patients treated with intensive insulin therapy from the onset of disease. Exp Clin Endocrinol Diabetes. 2010;118(8): 478-484.

14. Thorn LM, Forsblom C, Fagerudd J, et al; FinnDiane Study Group. Metabolic syndrome in type 1 diabetes: Association with diabetic nephropathy and glycemic control (the FinnDiane study). Diabetes Care. 2005;28(8):2019-2024.

15. Amato MC, Giordano C, Galia M, et al. Adiposity index (VAI): A reliable indicator of visceral fat function associated with cardiometabolic risk. Diabetes Care. 2010;12:920-922.

16. Williams KV, Erbey JR, Becker D, Arslanian S, Orchard TJ. Can clinical factors estimate insulin resistance in type 1 diabetes? Diabetes. 2000;49(4):626-632.

17. Gallagher D, Heymsfield SB, Heo M, Jebb SA, Murgatroyd PR, Sakamoto $Y$. Healthy percentage body fat ranges: An approach for developing guidelines based on body mass index. Am J Clin Nutr. 2000;72(3):694-701.

18. Diabetes Control and Complications Trial Research Group. Progression of retinopathy with intensive versus conventional treatment in the Diabetes Control and Complications Trial. Ophthalmology. 1995;102(4):647-661.

19. Montanya E, Fernandez-Castañer M, Soler J. Improved metabolic control preserved beta-cell function two years after diagnosis of insulindependent diabetes mellitus. Diabetes Metab. 1997;23(4):314-319.

20. Kurozumi A, Okada Y, Arao T, Tanaka Y. Excess visceral adipose tissue worsens the vascular endothelial function in patients with type 2 diabetes mellitus. Intern Med. 2016;55(21):3091-3095.

21. Sibley S, Palmer J, Hirsch I, Brunzell J. Visceral obesity, hepatic lipase activity, and dyslipidemia in type 1 diabetes. J Clin Endocrinol Metab. 2003;88(7):3379-3384.

22. den Engelsen C, van den Donk M, Gorter KJ, Salomé PL, Rutten GE. Advanced glycation end products measured by skin autofluorescence in a population with central obesity. Dermatol Endocrinol. 2012; 4(1):33-38.

23. Samborski $P$, Naskręt $D$, Araszkiewicz A, Niedźwiecki $P$, ZozulińskaZiółkiewicz D, Wierusz-Wysocka B. Assessment of skin autofluorescence as a marker of advanced glycation end product accumulation in type 1 diabetes. Pol Arch Med Wewn. 2011;121(3):67-72.

24. Dozio E, Briganti S, Delnevo A, et al. Relationship between soluble receptor for advanced glycation end products (sRAGE), body composition and fat distribution in healthy women. Eur J Nutr. 2017;56(8): 2557-2564. doi:10.1007/s00394-016-1291-0

25. Bjornstad P, Maahs D, Duca L, Pyle L, Rewers M, Johnson R. Estimated insulin sensitivity predicts incident micro- and macrovascular complications in adults with type 1 diabetes over 6 years: The coronary artery calcification in type 1 diabetes study. J Diabetes Complications. 2016;30(4):586-590.

26. Jia $X$, Olson D, Ross A, Wu L. Structural and functional changes in human insulin induced by methylglioxal. FASEBJ. 2006;20(9):1555-1557.

27. Monnier V, Bautista O, Kenny D, Sell D, Fogarty J, Dahms W; Diabetes Control and Complications Trial. Skin collage glycation, glycol oxidation, and crosslinking are lower subjects with long-term intensive versus conventional therapy of type 1 diabetes: Relevance of glycated collage products versus $\mathrm{HbA1c}$ as markers of diabetic complications. DCCT Skin Collagen Ancillary Study Group. Diabetes. 1999;48(4):870-880.

28. 2020 Guidelines on the management of diabetic patients: A position of Diabetes Poland. Clin Diabetol. 2020;9(1):24-26.

29. Mathieu C, Dandona P, Phillip M, et al. Glucose variables in type 1 diabetes studies with dapagliflozin: Pooled analysis of continuous glucose monitoring data from DEPICT-1 and -2. Diabetes Care. 2019;42: 1081-1087.

30. Dandona P, Mathieu C, Phillip M, et al; DEPICT-2 Investigators. Efficacy and safety of dapagliflozin in patients with inadequately controlled type 1 diabetes: The DEPICT-1 52-week study. Diabetes Care. 2018;41(9):2552-2559. 
31. Brownle M. Advanced protein glycosylation in diabetes and aging. Annu Rev Med. 1995;46:223-234.

32. Bucala $\mathrm{R}$, Vlassara $\mathrm{H}$. Advanced glycosylation end products in diabetic renal and vascular disease. Am J Kidney Dis. 1995;26(6):875-888.

33. Makita Z, Bucala R, Rayfield E, et al. Reactive glycosylation end products in diabetic uraemia and treatment of renal failure. Lancet. 1994; 343(8912):1519-1522.

34. Stitt A, He C, Friedman S, Scher L, Rossi P, Ong L. Elevated AGE-modified ApoB in sera of euglycemic, normolipidemic patients with atherosclerosis: Relationship to tissue AGEs. MolMed. 1997;3(9):617-627.

35. Berg T, Snorgaard O, Faber J, et al. Serum levels of advanced glycation end products are associated with left ventricular diastolic function in patients with type 1 diabetes. Diabetes Care. 1999;22(7):1186-1190.

36. Araszkiewicz A, Naskret D, Zozulinska-Ziolkiewicz D, et al. Skin autofluorescence is associated with carotid intima-media thickness, diabetic microangiopathy, and long-lasting metabolic control in type $1 \mathrm{dia}-$ betic patients: Results from Poznan Prospective Study. Microvasc Res. 2015;98:62-67.

37. Engerman RL, Kern TS. Progression of incipient diabetic retinopathy during good glycemic control. Diabetes. 1987;36(7):808-812.

38. Fishman SL, Sonmez H, Basman C, Singh V, Poretsky L. The role of advanced glycation end products in the development of coronary artery disease in patients with and without diabetes mellitus. Mol Med. 2018;24(1):59.

39. Ueno H, Koyama H, Fukumoto S, Tanaka S, Shoji T, Emoto M. Dialysis modality is independently associated with circulating endothelial progenitor cells in end-stage renal disease patients. Nephrol Dial Transplant. 2010;25(2):581-586.
40. Lutgers HL, Graaff R, deVries R, Smit AJ, Dullaart RPF. Carotid artery intima media thickness associates with skin autofluoresence in nondiabetic subjects without clinically manifest cardiovascular disease. Eur J Clin Invest. 2010;40(9):812-817.

41. Meerwaldt R, Hartog J, Graaff R, Huisman R, Links T, Hollander N. Skin autofluorescence, a measure of cumulative metabolic stress and advanced glycation end products, predicts mortality in hemodialysis patients. J Am Soc Nephrol. 2005;16(12):3687-3693.

42. Sobenin I, Tertov V, Koschinsky T, Bunting C, Slavina E, Dedov I. Modified low density lipoprotein from diabetic patients causes cholesterol accumulation in human intimal aortic cells. Atherosclerosis. 1993; 100(1):41-54.

43. Mulder D, Boer J, Graaff R, et al. Skin autofluorescence is inversely related to HDL anti-oxidative capacity in type 2 diabetes mellitus. Atherosclerosis. 2011;218(1):102-106.

44. Li S, Du M, Dolence E, et al. A ging induces cardiac diastolic dysfunction, oxidative stress, accumulation of advanced glycation end products and protein modification. Aging Cell. 2005;4(2):57-64.

45. Grimm S, Ott C, Hörlacher M, Weber D, Höhn A, Grune T. Advancedglycation-end-product-induced formation of immunoproteasomes: Involvement of RAGE and Jak2/STAT1. Biochem J. 2012;448(1):127-139.

46. Stratford F, Chondrogianni N, Trougakos I, Gonos E, Rivett A. Proteasome response to interferon-gamma is altered in senescent human fibroblasts. FEBS Lett. 2006;580(16):3989-3994.

47. Schram M, SchalkwijkC, Bootsma A, Fuller J, Chaturvedi N, Stehouwer C; EURODIAB Prospective Complications Study Group. Advanced glycation end products are associated with pulse pressure in type 1 diabetes: The Eurodiab Prospective Complications Study. Hypertension. 2005;46(1):232-237. 